\title{
ENTREVISTA COM ROBERTO SCHWARZ
}

Felipe Oliveira de Paula*

QUAIS OS ESTUDIOSOS BRASILEIROS QUE MAIS INFLUENCIARAM SUA FORMAÇÃO COMO CRÍTICO?

Li bastante a crítica de Mário de Andrade, Augusto Meyer, Anatol Rosenfeld, Paulo Emilio e Antonio Candido. No que respeita à sociedade brasileira, Joaquim Nabuco, Sergio Buarque de Holanda, Caio Prado Jr., Celso Furtado e Fernando H. Cardoso (na sua fase marxista). De diferentes maneiras, devo muito a todos.

$\mathrm{Na}$ outra banda, há os críticos-espantalho, que encarnam tudo aquilo que desejaríamos não ser. Também eles são muito educativos. *fopaula@yahoo.com.br

Doutorando em Estudos Literários pela UFMG.

EXISTE UMA TRADIÇÃO DE PENSAMENTO CRÍTICO E MATERIALISTA QUE PERPASSAM OS TRABALHOS DE GYÖRGY LUKÁCS, THEODOR ADORNO E WALTER BENJAMIM, QUE, POR SUA VEZ, PODEM SER VISTOS COMO COMPLEMENTARES, MAS DIFERENTES. CONTUDO, A PARTICULARIDADE DE CADA UM FAZ COM QUE OS “ESPECIALISTAS" TENDAM A DEIXAR DE LADO A LIGAÇÃO ENTRE ELES PARA VALORIZAR O AUTOR EM ESTUDO. PARA O SENHOR, O OUE APROXIMA E DISTANCIA ESSES PENSADORES E QUAL A IMPORTÂNCIA DELES PARA A CRÍTICA LITERÁRIA?

Os três dependem de Marx e são mestres da decifração social da forma artística. O grupo fica mais completo, para o meu gosto, embora menos homogêneo, se acrescentarmos Auerbach. Nos momentos altos, esta crítica traz verdadeiras revelações, em que a análise formal tem rendimento 


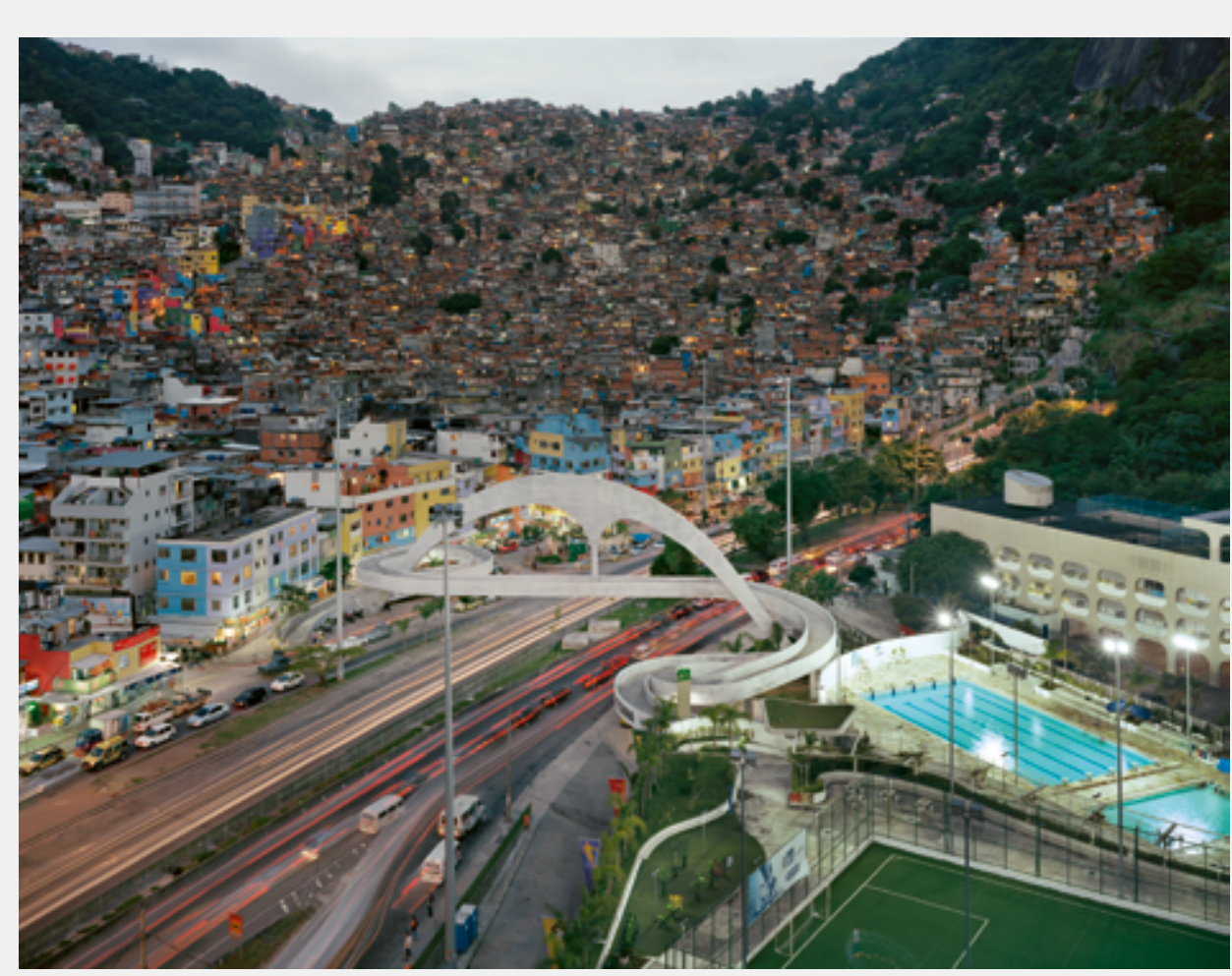

FIGURA 1

surpreendente, tanto estético como social. As diferenças ligam-se à história política do século XX, em especial à avaliação do movimento comunista e do stalinismo, ao qual Lukács pagou um tributo pesado. Hoje, passado o tempo, há uma parte das observações e argumentos do grupo que não envelheceu, formando um corpo razoavelmente consistente e muito iluminador, que vale a pena estudar em conjunto. A crítica ao capitalismo, a análise de classe e a reflexão sobre o impacto do progresso técnico sobre as artes, tudo combinado à aposta no teor de verdade histórica das formas, continuam vivas. Dito isso, nada do que estes autores escreveram se aplica ao Brasil tal e qual, e a reflexão sobre as diferenças é indispensável.

COMO O SENHOR CONCEBE A CRESCENTE DISPOSIÇÃO DOS ES TUDIOSOS DA LITERATURA OUE PROCURAM CORTAR OS VÍNCULOS ENTRE PALAVRA E SOCIEDADE? OUAL O PANORAMA DA CRÍTICA ATUAL?

O desejo de separar o estudo da literatura do estudo da sociedade não é novo, é até velhíssimo. É a ideia do Belo como região apartada, aonde a realidade não chega. Até onde vejo, trata-se de um patamar equivocado de especialização, difícil de sustentar. A literatura alimenta-se do que não é ela, e a crítica tem que acompanhá-la nesse movimento.

Noutro plano, a hegemonia econômica, militar, ideológica, universitária e midiática de uns poucos países, em especial os Estados Unidos, impõe ao resto do mundo linguagens prestigiosas, que não correspondem às histórias locais. Neste sentido, o corte entre palavra e sociedade de que você fala é uma tendência profunda, um traço da alienação contemporânea. $\mathrm{O}$ antídoto, ainda que esteja fora de moda, é a dialética. 
DECORRIDOS MAIS DE 30 ANOS DA PUBLICAÇÃO, O SEU TEXTO BEM-HUMORADO "19 PRINCIPIOS PARA A CRITICA LITERÁRIA" CONTINUA ATUAL. O SENHOR ACRESCENTARIA (OU MODIFICARIA) ALGUNS PRINCÍPIOS PARA O “BOM" CRÍTICO HOJE?

Os "19 princípios" são uma sátira à vida intelectual durante a ditadura. O golpe de 64 havia interrompido um processo notável de radicalização social e cultural, que estava transformando a consciência de si do país. Para te uma ideia da vitalidade desse movimento, basta assistir aos filmes do Cinema Novo. Pois bem, com a entrada em cena da repressão e da censura em grande escala, sobretudo depois do AI-5 em 1968, a reflexão de esquerda e o marxismo tiveram que sair de campo às pressas, sendo substituído de maneira mais ou menos atabalhoada por teorias menos marcadas politicamente, que estavam na moda na Europa nos Estados Unidos. O resultado foi um festival de novidades assimiladas sem muita crítica - a comédia, justamente, que procurei captar.

Hoje a ditadura passou e vivemos numa democracia de mercado, em tensão com as necessidades populares e sob a pressão da nova ordem mundial, a que uma parte da intelectualidade busca se acomodar. As questões não são as mesmas de 50 anos atrás, mas há muita coisa parecida. Fica por conta de vocês escrever a sátira do período, que todo dia está fazendo por merecer.
REAPROVEITANDO A IDEIA CENTRAL DO TEXTO “EXISTE UMA ESTÉTICA DO TERCEIRO MUNDO?", PUBLICADO EM OUE HORAS SÃO? É POSSÍVEL FALAR DE UMA "ESTÉTICA DO DESENVOLVIMENTO"?

Não sei se a questão que você está levantando chega a existir. Quando a ditadura terminou, em 1985, os veteranos do pré-64 quiseram retomar as suas lutas e bandeiras desenvolvimentistas anteriores. Aos poucos tiveram que reconhecer, contudo, que a realidade havia mudado, no mundo e aqui. $\mathrm{O}$ anti-imperialismo não era o mesmo, a luta de classes também não, a reforma agrária era outra, o campo socialista deixara de existir e o vanguardismo estético já não interessava, sem falar na presença avassaladora do capital. Uma parte da esquerda concluiu que o tempo do nacional-desenvolvimentismo havia acabado e que era hora de fazer as pazes com os americanos, de abandonar a luta de classes e acomodar-se com a indústria cultural e o agro-negócio.

Como a realidade não é linear, o período Lula-Dilma infligiu um desmentido parcial e moderadíssimo (que talvez esteja sendo derrotado neste momento) a essa posição: há sim um certo conflito entre o interesse nacional e a globalização, o antagonismo entre as classes não desapareceu, a parcialidade anti-esquerda da mídia é escandalosa etc.

Ainda assim, dada a correlação de forças desfavorável, qualquer radicalização figura como tabu, ao ponto de Dilma tentar um experimento de desenvolvimentismo em surdina,

\section{EM TESE BELO HORIZONTE}

v. 21

N. 1

JAN.-ABR. 2015

DE PAULA. Entrevista com Roberto Schwarz

P. 220-223 
sem qualquer mobilização nacional e muito menos popular. É claro que uma movimentação tão travada e quase secreta não pode ter desdobramentos estéticos interessantes, que por natureza solicitam a radicalidade. Tanto é assim que um período com ganhos sociais tão consideráveis como esse do PT no governo não chegou a produzir uma narrativa forte do Brasil, salvo nas superproduções grotescas das campanhas eleitorais. Voltando à sua pergunta, uma estética do desenvolvimento, se é que existe, não pode ser positiva, só pode ser crítica.

COMO O SENHOR ENXERGA A ATUAL RELAÇÃO ENTRE POLITICA E CULTURA NO CENÁRIO NACIONAL? E OUAL A INFLUÊNCIA DA INDÚSTRIA CULTURAL?

A política institucional está desmoralizada como raramente se viu, mas também a comercialização da cultura, a sua dependência de patrocínios empresariais e seu condicionamento por burocracias estatais se acentuaram $\mathrm{O}$ aprofundamento do capitalismo que estamos vivendo compromete tanto a política como a cultura, a ponto de nem notarmos mais que a dependência do dinheiro e a aceitação de alienações burocráticas é uma vergonha. Acho razoável dizer que os espaços de liberdade encolheram e que é preciso reconquistá-los, isto se houver a vontade necessária.
O MOVIMENTO DE JUNHO DE 2013 FOI CARACTERIZADO POR MANIFESTAÇÕES APARTIDÁRIAS E, A PRINCÍPIO, NÃO FOI ESPECIFICAMENTE CONTRA O GOVERNO DO PT. MESMO ASSIM, A DIREITA CONSEGUIU REVERTER O QUADRO E COOPTAR DE MANEIRA MAIS EFETIVA OS "SEM PARTIDOS". DE LÁ PARA CÁ, OS ELEITORES VEM ACEITANDO CADA VEZ MAIS A DIREITA E SE VOLTANDO CONTRA O GOVERNO DA PRESIDENTE DILMA ROUSSEFF. COMO O SENHOR AVALIA A SITUAÇÃO ATUAL DO BRASIL E, SOBRETUDO, DA NOVA FRENTE CONSERVADORA? JÁ É POSSÍVEL VISLUMBRAR ALGUMA REPOSTA/POSIÇÃO DA LITERATURA, OU DA CRÍTICA, DIANTE DESSE QUADRO?

De fato, a direita está avançando e gostaria de reduzir o PT a pouca coisa, para acabar com a resistência popular. Por outro lado, o PT se comprometeu a fundo com os funcionamentos que desmoralizam a política e dificultam as mobilizações de esquerda. A crítica não pode desconhecer esse aspecto anti-esquerda do PT, mas não pode também desconhecer que a liquidação do PT é um objetivo histórico da direita. É uma situação intrincada. 